\title{
Artículo Especial: El bienestar subjetivo como objetivo terapéutico
}

\author{
Subjective wellbeing as a therapeutic target
}

Federico I. García

"La felicidad de tu vida depende de la calidad de tus pensamientos" Marco Aurelio

Garcia F. El bienestar subjetivo como objetivo terapéutico. Evid Act Pract Ambul. Evid Act Pract Ambul. Jul-Sep 2013;16(3):90-91.

No es ajeno a los profesionales de la salud que desarrollan su actividad en contacto estrecho con el paciente, sobre todo en el escenario de la atención primaria de la salud (APS), enfrentarse a una serie de problemas vinculados con la salud mental que ponen de manifiesto la ausencia de bienestar.

Cuadros como trastornos de ansiedad, depresiones, distimias, fibromialgias, cefaleas, astenias, entre otros, pacientes policonsultadores, que consumen una gran cantidad de recursos, traducen un estado de malestar, que no siempre logramos resolver utilizando las herramientas que nos brinda la farmacología, por más adelantos y desarrollos de nuevos y eficaces medicamentos, ni las diferentes psicoterapias. Y cuando logramos mejorar este malestar nos quedamos demasiado a menudo con la sensación de una muy probable recaída.

Recientemente, un estudio, asoció el distress psicológico (trastorno de ansiedad y depresión), ya no sólo con la afectación de la calidad de vida, sino con un aumento del riesgo de la mortalidad global, habiendo una fuerte evidencia de efecto dosis-respuesta, incluso con bajos niveles de distress ${ }^{1}$.

Hoy más que nunca, es necesario considerar el bienestar subjetivo como un objetivo terapéutico.

Todos somos conscientes del inmenso poder que posee la mente y su enorme capacidad de producir enfermedad. Durante décadas tanto psicólogos como psiquiatras y otras disciplinas vinculadas con la salud mental han puesto su esfuerzo en el estudio de la patogenia, manejo y tratamiento de estas afecciones, obteniendo grandes beneficios, a juzgar por los progresos vislumbrados en esa área en los últimos 50 años. Sin embargo, aun no se ha llegado a comprender y valorar en su total dimensión el poder de la psiquis como instrumento terapéutico.

Mucho se ha estudiado e investigado sobre los efectos nocivos del stress como causa de afecciones, la asociación de cuadros de depresión y duelos con patologías cardiovasculares e incluso el desarrollo de tumores, sin embargo, es escasa la investigación que vincula el estado de bienestar, con la ausencia de enfermedad. La misma capacidad que tiene la mente para generar enfermedad, la posee para sanar. El poder sanador de la mente es intuido, percibido, pero aun no ha sido explorado ni explotado en su total dimensión.

¿Cuáles son los rasgos de la personalidad que se asocian al bienestar? ¿Cuáles son los factores externos o internos que impactan de manera positiva o negativa en nuestro ánimo?

¿En qué medida los pensamientos positivos y el optimismo afectan nuestro estado de bienestar?

¿Qué relación existe entre éste estado subjetivo y las dolencias que acostumbramos tratar?

¿Con qué herramientas contamos para mejorar el estado de bienestar de nuestros pacientes?

Son muchos los interrogantes que nos planteamos intentando descifrar la misteriosa y entrañable trama que constituye nuestro pensar y sentir. Podemos hablar de "tipos de personalidad", de "caracteres", de rasgos más o menos constantes que constituyen nuestro ser y nos acercan o alejan en mayor o menor medida al estado de bienestar.

El desafío que afrontamos los que trabajamos en APS es buscar y encontrar respuestas a estos y un sin fin de interrogantes que iluminen y orienten nuestros esfuerzos tendientes a promover el estado de bienestar individual y comunitario que cons- tituye sin duda una poderosa forma de promoción y prevención de la Salud.

\section{¿Qué es el bienestar subjetivo?}

Decimos que un individuo posee un alto bienestar subjetivo si expresa satisfacción con su vida, frecuentes emociones positivas y pocas emociones negativas. Por el contrario, si el individuo expresa insatisfacción con su vida y experimenta pocas emociones positivas y muchas negativas, su bienestar es bajo.

\begin{tabular}{|l|l|}
\multicolumn{1}{|c|}{ Tipos de afecto $^{2}$} & \multicolumn{1}{|l|}{ Afecto negativo } \\
\hline Afecto positivo & - culpa o vergüenza \\
\hline - alegría & - tristeza \\
- euforia & - ansiedad o preocupación \\
- satisfacción & - enfado \\
- orgullo & - estrés \\
- cariño & - depresión \\
- felicidad & - envidia \\
- éxtasis &
\end{tabular}

Existen varias teorías que enfatizan diferentes aspectos para explicar el bienestar subjetivo:

1- La Teoría de la Autodeterminación (Ryan y Deci 1985, $1991)^{3,4}$ postula que las personas pueden ser proactivas y comprometidas o inactivas o alienadas, dependiendo de las condiciones sociales en las que se desarrollan y funcionan. Los seres humanos tendrían ciertas necesidades psicológicas innatas que serían la base de una personalidad automotivada e integrada y los ambientes sociales en que se desarrolla fomentarían o dificultarían estos procesos positivos. Utilizando métodos empíricos se identificaron tres necesidades psicológicas innatas: ser competentes, la autonomía y las relaciones interpersonales. La gratificación de estas necesidades son una clave predictiva del bienestar subjetivo.

2- El Modelo Multidimensional (Ryff 1989) ${ }^{5}$ nos propone que el funcionamiento psicológico estaría conformado por una estructura de seis factores: autoaceptación, crecimiento personal, propósito de vida, relaciones positivas con otros, dominio medioambiental y autonomía, cambiando la experiencia subjetiva de bienestar a lo largo de la vida, predominando uno u otro factor en las distintas etapas del ciclo vital. El desarrollo de estos factores predecirían un mayor bienestar.

3- El Modelo de Acercamiento a la Meta (Brunstein 1993; Cantor y cols. 1991; Diener y Fujita 1995, entre otros) ${ }^{6}$ considera a la metas (estados internalizados deseados por el individuo) y los valores como guías principales de la vida, mientras que las luchas personales (lo que los individuos hacen característicamente en la vida diaria) son metas de un orden inferior. Este modelo plantea que los marcadores de bienestar varían en los individuos dependiendo de sus metas y sus valores (Oishi 2000) ${ }^{7}$.

4- La Teoría del Flujo (Csikszentmihalyi) ${ }^{8}$ indica que el bienestar estaría en la actividad humana en sí y no en el logro de la meta final. Lo que el individuo hace, produce un sentimiento especial de flujo. La actividad que produce dicho sentimiento, es lo que se refiere al descubrimiento constante que esta haciendo el individuo de lo que significa "vivir".

"Ayudar a la gente a manejar mejor sus sentimientos perturbadores (la ira, la ansiedad, la depresión, el pesimismo y la soledad), es una forma de prevención de la enfermedad"

Daniel Goleman 
Otra área de investigación es la personalidad.

¿Qué distingue a un individuo feliz de otro que no lo es? ¿Qué rasgos de la personalidad podemos asociar a un mayor bienestar?

El concepto de personalidad está formado por constructos hipotéticos que ayudan a explicar la conducta de los sujetos. Los factores ambientales en interacción con factores temperamentales (heredados) y caracteriales (aprendidos) constituyen una explicación necesaria y suficiente para los clínicos que siguen un modelo de la personalidad (Tous 1989) ${ }^{9}$.

La personalidad es uno de los predictores más fuertes y consistentes del bienestar subjetivo. La asociación personalidadbienestar se sostiene en un gran número de investigaciones, postulándose diversas teorías para explicarlo. Tellegen y $\mathrm{Col}^{10}$, en estudios realizados en gemelos univitelinos y mellizos bivitelinos intento explicar como inciden los genes en el bienestar, concluyendo que los genes son responsables de aproximadamente el $40 \%$ de las emociones positivas y el $55 \%$ de las variaciones emotivas negativas. También refiere que estas estimaciones de la herencia se influencian por la variabilidad medioambiental. Los rasgos de la personalidad que recibieron más atención teórica y empírica respecto al bienestar son la extraversión y el neuroticismo. Según Costa \& McCrae ${ }^{11}$, la extraversión influye en el afecto positivo y el neuroticismo en el afecto negativo. La extraversión es un recurso que ayuda al bienestar probablemente por ayudar a los individuos a lograr ciertos tipos de metas, como tener amigos y un mayor número de relaciones sociales.También la autoestima se asocia al bienestar y la rumiación de eventos negativos predisponen al malestar. El neuroticismo o vulnerabilidad a la neurosis, implica una baja tolerancia para el estrés tanto de carácter físico (ejemplo, el dolor) como psicológico (ejemplo, la frustración). El neuroticismo hace mención a la dimensión de estabilidad/inestabilidad emocional de la persona.

Los investigadores dedicados al estudio del bienestar subjetivo centraron su atención en los procesos de adaptación. Parten de la premisa de la determinación biológica de los rasgos de la personalidad, refiriéndose buena parte de los estudios al temperamento, el cual por tener una mayor carga genética tiene un poderoso efecto sobre el bienestar subjetivo.

Según los supuestos teóricos de Eysenck, la personalidad puede ser resumida en tres dimensiones fundamentales: extraversión, neuroticismo y psicoticismo. Los individuos que tienen altos puntajes en extraversión se caracterizan por ser sociables, asertivos, vivaces y propensos a la búsqueda de sensaciones; los que poseen altos niveles de neuroticismo, son ansiosos, deprimidos, emocionales y con baja autoestima; mientras los puntajes altos en psicoticismo evidencian agresividad, conducta antisocial, egocentrismo y creatividad.
Será interesante evaluar cómo las estrategias cognitivas pueden influir sobre la personalidad y de esa forma alcanzar un mayor estado de bienestar. Lograr el refuerzo de las evaluaciones positivas del entorno, permitiendo una participación activa del sujeto, con una valoración más optimista, impactaría en el estado de salud del individuo de manera positiva.

La relación personalidad / bienestar subjetivo, no puede ser examinada abstrayendo rasgos aislados de la personalidad, necesariamente se debe analizar integralmente, como un todo. Este es un principio básico de la Teoría General de los Sistemas que postula la falacia de interpretar subsistemas aislados, por carecer de relevancia su papel, fuera del sistema al que pertenece.

Por lo tanto, el bienestar no estaría determinado por la posesión de determinado rasgo, sino por el resultado de complejas relaciones que se dan como un todo, interactuando un considerable número de variables.

Algunas de las variables microsociales que con más consistencia predicen el bienestar, según diversos estudios son:

- el status marital: las personas casadas o unidas reportan mayores niveles de felicidad que las solteras, divorciadas o viudas cuando constituyen hogares funcionales. Algunos autores reportaron diferencias significativas en los niveles de satisfacción con la vida entre individuos que fueron educadas en hogares con conflictos y los que crecieron en familias con relaciones adecuadas.

- los éxitos académicos y la intimidad constituyen poderosos predictores de bienestar en estudiantes universitarios.

- la participación social sobre todo en las personas jubiladas. - la satisfacción con el trabajo en los que se encuentran en edad laboral.

- La pareja, la familia, los grupos de referencia y pertenencia constituyen poderosas fuentes de apoyo emocional, informativo y funcional para las personas (De Ridder y Schreus 1996) ${ }^{12}$ y su ausencia un factor de riego de insatisfacción y malestar.

A pesar de la fuerte impronta de la psicología positiva en el estudio de factores como la felicidad y el bienestar, que en ocasiones tiende a descomponer y atomizar el objeto buscando la asociación entre diversas variables, desnaturalizando el complejo sistema que implica el pensar y sentir del individuo, el estudio del bienestar subjetivo ha dado una nueva mirada centrada en las cualidades humanas positivas, ha destacado la importancia de la subjetividad en la evaluación de la vida y la posibilidad de la promoción de determinados factores y rasgos de la personalidad que se asociarían a una vida mas plena y saludable.

Recibido el 01/06/2013 y aceptado el 15/06/2013

\section{Referencias}

1.Tom CR, Emmanuel S, Mark H, John MS, Mika K, Batty GD. Association between psychological distress and mortality: individual participant pooled analysis of 10 prospective cohort studies. BMJ. 2012;345

2. Diener, E., Suh, M., Lucas, E. \& Smith, H. Subjective well-being: Three decades of progress, Psychological Bulletin, 1999;125(2):276-302.

3. Deci, E.L., \& Ryan, R.M. (1985). Intrinsic motivation and selfdetermination in human behavior. New York: Plenum

4. Deci, E.L., \& Ryan, R.M. (1991). A motivational approach to self: Integration in personality. En R. Deinstbier (Ed.), Nebraska symposiumon motivation: Vol. 38. Perspectives on motivation (237-288). Lincoln, NE: University of Nebraska Press.

5. Ryff, C. D. (). Happiness Is everything, or is it? Explorations on the meaning of psychological well-being. Journal of Personality \& Social Psychology1989;57(6):1069-1081. 6. Diener, E; Diener, M; Diener, C. Factors predicting the subjective well-being of nations. Journal of Personality and Social Psychology, 1995;69(5): 851-864.

7. Oishi, S. (2000). Goals as Cornerstones of subjective well-being: Linking individuals and cultures. En: Diener, E. y Suh, E. M., (Eds.), (2000) Culture and Subjective Wellbeing, pp 87 - 112, Cambridge, MA: MIT Press).

8. Csikszentmihalyi, M. (1999). Fluir. Una psicología de la felicidad. Barcelona: Ed. Kairos, $7^{\circ}$ ed. (Orig. 1990 )

9. Tous, J.M (1989) : Modificación de conducta, personalidad y psicología clínica. Análisis y Modificación de Conducta, 15, 221-237.

10. Tellegen, A., Lykken, D. T., Bouchard, T. et al. Personality similarity in twins reared apart

and together. Journal of Personality and Social Psychology 1988;54:1031-9.

11. Costa, P. T., McCrae, R. R. \& Zonderman, A. B.Environmental and dispositional influences on well-beingLongitudinal follow-up of an American national sample. British Journal of Psychology 1987;78:299-306.

12. De Ridder, D. y Schreus, K. Coping, social support and chronic disease: a research agenda. Psychology, Health and Medicine. 1996;1(1):71-82. 